\title{
Creative Coping: A Cognitive-Behavioral Group for Borderline Personality Disorder
}

\author{
Claudia R. Miller, William Eisner, and Charlotte Allport
}

\begin{abstract}
Patients with borderline personality disorder (BPD) pose major therapeutic challenges to mental health professionals. Effective and practical treatment of the patient with BPD is needed in short-term inpatient settings, and psychiatric nurses are in a unique position to implement innovative treatment strategies for the borderline patient. The Creative Coping Group is a practice model designed by psychiatric nurses for patients with BPD, using a cognitive-behavioral framework. It is a group therapy intervention based on Linehan's Dialectical Behavior Therapy (DBT) that addresses the ineffective coping of patients with BPD that results in chronic suicidal behavior. Linehan's framework focuses on deficits in emotional control, interpersonal effectiveness, and distress tolerance. The objective of the group sessions is to foster insight and awareness into symptoms, feelings, and behaviors through psychoeducation, group exercises, discussion, and homework assignments.
\end{abstract}

Copyright (C) 1994 by W.B. Saunders Company

$\mathbf{P}$ ATIENTS WITH borderline personality disorder (BPD) pose major therapeutic challenges to mental health professionals. Because psychiatric nurses working with hospitalized patients with BPD frequently experience tension, exhaustion, and burnout (Piccinino, 1990), specific nursing interventions that target the patient's core problems are essential. Because hospitalization may be necessary for patients with BPD during regressions manifested by suicidal or self-destructive behavior, treatment must provide for the patient's safety, as well as facilitate effective coping mechanisms.

Historically, treatment for patients with BPD has been intensive exploratory psychotherapy but this type of treatment is long-term, and not compatible with today's economic constraints in mental health care. Group therapy for patients with BPD is a treatment modality that has had favorable

From the Department of Psychiatric Nursing, The University of Michigan Medical Center, Ann Arbor, MI.

Address reprint requests to Claudia $R$. Miller, RN, MS, Department of Psychiatric Nursing, The University of Michigan Medical Center, Ann Arbor, MI 48109-0020.

Copyright $\mathbb{C} 1994$ by W.B. Saunders Company

0883-9417/94/0804-0009\$3.00/0 outcomes for this population but has not been extensively used or studied. In group therapy, problematic behaviors of the inpatient with BPD can be dealt with specifically, to maximize therapeutic effectiveness, within time constraints.

This article describes a specific cognitivebehavioral group therapy, the Creative Coping Group, which was developed in conjunction with other structural elements in the BPD program at the University of Michigan Medical Center. The Creative Coping Group has been used effectively as an adjunctive structuring modality within the "Interrupted Inpatient Treatment of Borderline Personality Disorder Program" (Silk, Eisner, Allport, Demars, Miller, Justice, \& Lewis, 1992). This program provides for a focused time-limited approach that maximizes the benefits of short-term hospitalization for patients with BPD. In addition to the Creative Coping Group, the "Interrupted Inpatient Treatment of Borderline Personality Disorder Program"' includes the following: preadmission contracts; a focus on reducing symptoms related to the current crisis; a goal-oriented inpatient behavioral treatment contract; the setting of a discharge date early in hospitalization; and the delin- 
eation of specific goal-oriented criteria for readmission. Psychiatric nurses often find that the frustration of working with hospitalized patients with BPD occurs because " nursing care guidelines for BPD are often nonspecific and reactive rather than proactive"' (Gallop, 1992, p. 179). By having specific strategies with which to conceptualize and treat the complexities of the individual with BPD, both the patient and nurse have a greater sense of control and empowerment.

\section{LINEHAN'S FRAMEWORK}

Cognitive behavioral approaches are "wellsuited to borderline patients because of their explicit focus on self-regulation" (Westen, 1991, p. 218). Therefore, a cognitive-behavioral framework, Linehan's (1987a, 1987b, 1987c) Dialectical Behavior Therapy (DBT) was chosen as a model for the Creative Coping Group to address the core problems and ineffective coping of patients with BPD.

Linehan (1987a, 1987b, 1987c) proposes that the primary dysfunction of the individual with BPD is one of inadequate affect regulation. Consequently, an affective instability yields behavioral instability, chaotic interpersonal relations, selfinstability, and cognitive instability. In addition, to cope with their psychic distress, patients with BPD frequently engage in suicidal behaviors. Linehan (1987a) developed DBT to address the ineffective coping of individuals with BPD which may result in chronic suicidal behavior. The Creative Coping Group uses Linehan's framework, to replace maladaptive behaviors, specifically suicidal behaviors, with effective coping techniques in the areas of emotional control and regulation, interpersonal effectiveness, and distress tolerance.

\section{THE CREATIVE COPING GROUP STRUCTURE AND PROCESS}

The Creative Coping Group meets daily Monday through Friday for a 2-week period. The ten groups are run on a continuous basis, and patients enter at whatever place that the sequence is in when they arrive on the unit. Each group session is 45 minutes long. The objective of the group is to foster insight and awareness into symptoms, feelings, and behaviors through psychoeducation, group exercises, discussion, and homework assignments. The group is comprised of 10 sessions within three modules, and is structured as follows:
Module 1-Emotional Control and Regulation; Module 2-Interpersonal Effectiveness; and Module 3-Distress Tolerance.

\section{Module 1: Emotional Control and Regulation}

Emotional control and regulation is the focus of the first module. Linehan (1993a) describes the individual with BPD as emotionally vulnerable. Patients with BPD are highly sensitive to emotional stimuli and respond intensely to such stimuli. Linehan asserts that there may be a biological predisposition for this, or it may be in response to an invalidating environment. Individuals with BPD may have had their feelings invalidated, and subsequently do not know how to label or control their emotions adequately, how to tolerate emotional distress, or when to trust their own emotional responses. Frequently, patients with BPD express that they "don't know how they feel." They vacillate between shutting down or avoiding their feelings (psychic numbing), to reacting intensely to emotional stimuli. The suicidal and other self-destructive behaviors are usually maladaptive responses to their overwhelming negative affect (Linehan, 1993b).

The five sessions within the emotional control and regulation module assist patients with BPD to identify the emotions they are experiencing, and teach skills to reduce intense emotional responses.

Session 1: Feelings 1 . In the first session entitled "Feelings 1," basic principles about emotions are taught. "Myths about Emotions" (Linehan, 1993b, p. 136) such as, "there is a right way to feel in every situation" are examined and challenged. Group members learn that all emotions are valid, and that a safe person with whom they can share their feelings is important for the validation experience. Group members are encouraged to designate their primary nurse as a safe person with whom they can practice expression of their feelings, and get validation in return. They need to inform their safe person what it is they want or need from them, to feel validated. For example, the patient may simply want their safe person to actively listen to them, and not give feedback. Or, they may want assistance in clarification and identification of their emotions, using a handout provided in group. Linehan's (1993b) form for "Observing and Describing Emotions" (p. 162) is given as a tool to be used daily. This form helps the patient to identify the emotion they experi- 
enced, as well as what triggered the emotion, and the effect and function of the emotion.

Session 2: Feelings 2. The next session on emotions, entitled "Feelings 2," provides skills to prevent or cope with feelings that may overwhelm and lead to suicidal behaviors. Group members identify those thoughts or situations that trigger intense emotions for them, and then work on preparing for these emotional situations. We use Linehan's (1993b) framework for reducing emotional vulnerability which focuses on observing the emotion, taking a time-out to get inner distance, and distracting themselves for the moment. The patient must determine what activities could be initiated to distract them from the intense emotion, and ultimately, from engaging in self-destructive behaviors. Patients then list their activities such as going on a walk, taking a warm bath, or calling a friend. Each group member makes a personalized plan of action to use when they begin to feel overwhelmed, and frequently carry their plan with them. Then, when an intense emotion is triggered while on the inpatient unit, the primary nurse will assist the patient in determining what has been tried, and problem-solve the unsuccessful attempts at distraction.

Session 3: Anger. Because the person with BPD is prone to have inappropriate, intense anger or lack of control of anger (American Psychiatric Association, 1987), a third session was developed to address anger. The objectives of this session are as follows: to have the client identify their patterns in expressing anger; to understand that anger and aggression are not the same thing; and to explore new ways to express anger. Group members participate in exercises that use confrontation and assertiveness techniques (Linehan, 1993b). Roleplaying of situations that may elicit an angry reaction are practiced. An example of a role-play situation is one in which the patient perceives rejection by her therapist because the therapist repeatedly looks at her watch during a therapy session. Each group member practices confronting the behavior, expressing their feelings, and presenting a request to the person they are confronting. However, because situations don't always run as smoothly as in the role-plays, other problemsolving techniques are explored in the next session.

Session 4: Problem-solving. Another way to gain better emotional control is to become better at problem-solving. Unfortunately for the individual with BPD, suicide, or parasuicidal behaviors (Linehan, 1991) have often been their solutions for problem-solving. The objective of the fourth session is to assist group members to see the connection between problems and emotions, and learn basic problem-solving skills. The tool used in this session is Kanfer and Schefft's (1988, p. 108) "Six Think Rules"' which focus on behaviors, solutions, strengths, limited goals, alternative plans, and future outcomes. Situations that may be problematic for the patient with BPD are role-played in the session, using the techniques provided. An example of a situation would be the individual's therapist going on vacation. Group members would describe their interpretation of the event, and $o b$ serve which interpretations are causing intense emotions. Their interpretation of the event is then addressed during the fifth session that teaches cognitive restructuring.

Session 5: Cognitive restructuring. In cognitive restructuring we assist the patient in becoming more aware of problematic assumptions and beliefs that cause emotional distress. Patients with BPD characteristically think very dichotomously. "Dichotomous thinking plays an important role in the extreme reactions and abrupt mood swings characteristic with borderline personality disorder" (Beck \& Freeman, 1990, p. 189). Beck \& Freeman (1990) assert that with BPD, three basic assumptions are uncovered in cognitive therapy: "The world is dangerous and malevolent; I am powerless and vulnerable; and I am inherently unacceptable" (p. 186). We use Linehan's (1983b, p. 118) worksheet "Myths About Interpersonal Effectiveness" to identify and refute irrational thoughts that usually manifest themselves within Beck's three basic assumptions. These techniques challenge the characteristic dichotomous thinking of patients with BPD, and assist them to see the ambiguity of situations, as well as the advantages of being flexible, to attain emotional control.

Emotional control is very challenging for individuals with $\mathrm{BPD}$ in their relationships, as instability in interpersonal relationships seem to be one of the hallmarks of BPD (Bell, Billington, Cicchetti, \& Gibbons, 1988). Effective ways of connecting and relating to these patients is a necessary challenge for mental health professionals, because individuals with BPD frequently alienate them- 
selves from others with their maladaptive style of relating.

\section{Module 2: Interpersonal Effectiveness}

Session 1: Needs assessment. In the first session "'needs assessment," common human needs are identified, using Bradshaw's "Basic Dependency Needs" tool (1988, p. 57). We have group members assess which needs they generally have difficulty getting met, and identify factors that may interfere with getting their needs met. Common beliefs that serve as barriers to getting their needs met include patients' believing, "I don't deserve to get my needs met; I can't cope on my own; I need someone to rely on; or, I must subjugate my wants to the desires of others or they'll leave me or attack me" (Beck \& Freeman, 1990, p. 185). Group members identify their own beliefs about needs, and make challenge statements to refute these myths, thereby identifying corrective actions to more successfully attain their needs.

Session 2: Needs effectiveness. In the second session "needs effectiveness," adaptive skills versus a maladaptive style of getting needs met is taught. Persons with BPD frequently display behaviors which staff label as manipulative. However, it is important for professionals working with patients with BPD to understand that these behaviors often result because, "the borderline individual learns that either an extreme emotional display or presentation of extreme circumstances is necessary to provoke a validating environmental response" (Linehan, 1993, p. 72). Consequently, group members are provided with situations in which getting their needs met may be frustrated. These situations are role-played, using Linehan's ( 1993b, p. 125) "Guidelines for Objectives Effectiveness: Getting What You Want" tool. This tool uses an easy to remember acronym, "DEAR MAN" which stands for Describe, Express, Assert, Reinforce, Mindfully, Appear confident, and Negotiate. We also address the fact that sometimes one's needs do not get met all the time, and that skills taught in other sessions such as problemsolving or distress tolerance can be implemented, because overwhelming emotions may ensue.

Session 3: Relatedness. Because individuals with BPD characteristically lack internal relatedness, they often describe chronic feelings of emptiness and boredom. They also have difficulty being alone, and are highly sensitive to loss, rejection, and abandonment (Westen, 1991). This internal sense of disconnectedness leads to unstable relationships, as they try to fill the void by developing sudden intense relationships marked by clinging dependency. Often as these individuals move closer to others, they fear domination, exploitation, abuse, or abandonment, and subsequently, they feel rage and behaviorally withdraw. When this withdrawal occurs, the overwhelming feeling of abandonment often returns. These oscillations of attachment (Melges \& Swartz, 1989) cause chaos in relationships. The third session addresses "relatedness" and is largely psychoeducational. This session attempts to increase patient's self-awareness of their own relatedness or connectedness, and assists them in identifying triggers of core issues and patterns in relatedness. Group members begin to identify their own experiences with relatedness, discussing what it means to be connected and disconnected with themselves and others. The group is assisted in identifying ways that can increase connectedness with themselves and others, by examining four relatedness competencies: sense of belonging; reciprocity; mutuality; and synchrony (Hagerty, Lynch-Sauer, Patusky, \& Bouwsema, 1993). It is believed that when an individual experiences higher levels of belonging, reciprocity, mutuality, and synchrony in relationships, then connectedness with that person is greater. Therefore, these competencies are used as processes involved in assessing and promoting relatedness states. For example, a person's sense of belonging may be enhanced by being in the Creative Coping Group, and they may then pursue other therapy or support groups. Reciprocity, or the give-and-take in relationships is discussed, as well as mutuality, or the commonality in relationships. Synchrony, rhythmic patterns, or one's personal experience with congruence in relation to oneself, others, and environment is also discussed as an aspect of relatedness. It is also emphasized in the group that one must identify a comfortable distance in relationships. The concept of comfortable distance is elaborated in the next session which focuses on "boundaries."

Session 4: Boundaries. Patients with BPD frequently describe pathological family boundaries in their childhood experiences (Goldberg, Mann, Wise, \& Segall, 1985; Herman, Perry. \& van der Kolk, 1989; Ogata, Silk, Goodrich, Lohr, Westen, \& Hill, 1990). Consequently, individuals may ex- 
hibit either very rigid boundaries or loose boundaries which prevent a comfortable distance with others. Personal boundaries are taught, in the group, to be necessary in relationships, because they offer protection, comfort, and safety. A "Personal Boundaries Survey" (Whitfield, 1990, p. 169-171) is distributed to group members to assist them in identifying the strengths and limitations of their own personal boundaries.

After group members complete the survey, there is a discussion facilitating recognition of feelings and conflicts related to boundaries. Abandonment issues are frequently a topic elicited in the discussion. A second worksheet on boundaries is then distributed. This worksheet contains exercises in setting personal boundaries in advance, changing and negotiating boundaries, and defending one's personal boundaries (Woititz \& Garner, 1990). When group members sharc their experiences in this session, as well as any of the other group sessions, the group leaders role-model how to validate feelings, and often other group members begin to validate and support each other. The group is an important means by which individuals with BPD can be validated and soothed. But when patients are not in a group they also need methods by which they can soothe themselves.

\section{Module 3: Distress Tolerance}

Individuals with BPD exhibit a deficiency in the ability to self-soothe, as manifested by their intolerance of being alone (Westen, 1991). Consequently, the patient needs to learn to be a surrogate mother to his or her own "inner child" (Vaillant, 1992). Group members begin to identify their selftalk which is frequently invalidating and selfdeprecating. A common thought group members identify is, "I shouldn't feel that way." Group members then keep a log of their invalidating selftalk and are given appropriate challenges such as the statement, "All feelings are valid." Cognitive techniques such as, visualizing the word "STOP," when their negative self-talk begins, and replacing it with an affirmation, or positive statement is practiced in group. For example, the negative statement of "I'm stupid" would be replaced by the challenge, "I'm doing the best that I can" or "I'm competent and learn from my mistakes." Group members must write an affirmation to themselves every morning, and share with the group how it was used during the course of the day.
These daily self-soothing statements are encouraged as a means by which they are not only nurturing themselves but also as a means of connecting with themselves. In this session, we also emphasize the use of relaxation techniques, such as deep breathing, progressive relaxation, and imagery. Group members also identify and share their own self-soothing techniques that they have found helpful.

\section{REINFORCEMENT OF COPING SKILLS: A MILIEU PERSPECTIVE}

Learning coping skills taught in the group does not necessarily mean they will be used when the group session has ended. As with any new skill, the techniques need to be practiced repeatedly. Having the support of the nursing staff is essential for the continuity and reinforcement of the coping skills taught in the group. Group members have daily homework assignments from the group to be shared in the next session. The evening staff nurse will offer assistance in promoting completion of the homework assignment for the following day. When the patient with BPD experiences distress, within the milieu, and may be feeling selfdestructive, it is important that they are asked, "What coping skills are you using?" and that they are helped to implement what they have learned.

\section{CONCLUSION AND FUTURE DIRECTIONS}

Effective and pragmatic forms of treatment that address the problematic behaviors of BPD have been scarce. Psychiatric nurses have frequently been frustrated by vague nursing interventions that do not specifically and consistently meet the needs of patients with BPD. Group therapy for patients with BPD is a valuable treatment modality that psychiatric nurses can implement in their setting. The cognitive behavioral approach of the Creative Coping Group has been used to provide opportunities for insight into the patient's behavior, as well as for the management of self-destructive behavior. With the implementation of the Creative Coping Group, nursing staff no longer feel in a reactive position toward the patient with $\mathrm{BPD}$, but rather feel empowered, with skills to offer, and are more willing to engage with the patient.

The psychiatric nurse is in a unique position to investigate and implement group therapy as a means of enhancing the quality of care for this 
challenging population. Feedback from borderline patients that have been in the Creative Coping Group has been positive, and a controlled outcome research study of the effectiveness of the group is currently in process. The study will evaluate the effectiveness of the group on psychiatric and social adjustment symptoms, as well as suicidality. Consequently, an outpatient group could then be developed to provide the opportunity for reexposure to the Creative Coping Group skills.

\section{ACKNOWLEDGMENT}

The authors gratefully acknowledge Maureen Lewis, RN and Dr. Kenneth Silk for their support in the development of the Creative Coping Group. We also thank Marge Calarco, $\mathrm{RN}, \mathrm{PhD}$, for her contributions in the preparation of this manuscript.

\section{REFERENCES}

American Psychiatric Association. (1987). Diagnostic and statistical manual of mental disorders (3rd ed. rev.). Washington, DC: Author.

Beck, A., \& Freeman, A. (1990). Cognitive Therapy of Personality Disorders. New York: Guilford.

Bell, M., Billington, R., Cicchetti, D., \& Gibbons, J. (1988). Do object relations deficits distinguish BPD from other diagnostic groups? Journal of Clinical Psychology, 44. $511-516$.

Bradshaw, J. (1988). Healing the Shame that Binds You. Deerfield Beach, FL: Health Communications.

Gallop, R. (1992). Self-destructive and impulsive behavior in the patient with a borderline personality disorder: $R e-$ thinking hospital treatment and management. Archives of Psychiatric Nursing, 6(3), 178-182.

Goldberg, R., Mann, L., Wise, T., \& Segall, E. (1985). Parental qualities as perceived by borderline personality disorders. Hillside Journal of Clinical Psychiatry, 7(2), 134-140.

Hagerty, B., Lynch-Sauer, J., Patusky, K., \& Bouwsema, M. (1993). An emerging theory of human relatedness. Image: Journal of Nursing Scholarship, 25(4), 291-296.

Herman, J., Perry, C., \& van der Kolk, B. (1989). Childhood trauma in borderline personality disorder. American Journal of Psychiatry, 146(4), 490-495.
Kanfer, F., \& Schefft, B. (1988). Guiding the Process of Therapeutic Change. Champaign, IL: Research Press.

Linehan, M. (1987a). Dialectical behavior therapy for borderline personality disorder: Theory and method. Bulletin of the Menninger Clinic, 51, 261-276.

Linehan, M. (1987b). Dialectical behavior therapy: A cognitive-behavioral approach to parasuicide. Journal of Personality Disorders, I, 328-333.

Linehan, M. (1987c). Dialectical behavior therapy in groups: Treating borderline personality disorders and suicidal behaviors. In C.M. Brady (Ed.). Women in groups. New York: Springer.

Linehan, M. (1991). Cognitive-behavioral treatment of chronically parasuicidal borderline patients. Archives of General Psychiatry, 48, 1060-1064.

Linehan, M. (1993a). Cognitive behavioral treatment of borderline personality disorder. New York: Guilford.

Linehan, M. (1993b). The skills training manual for treating borderline personality disorder. New York: Guilford.

Melges, F. \& \& Swartz, M. (1989). Oscillations of attachment in borderline personality disorder. American Journal of Psychiatry, 146(9), 1115-1120.

Ogata, S., Silk, K., Goodrich, S., Lohr, N., Westen, D., \& Hill, E. (1990). Childhood sexual and physical abuse in adult patients with borderline personality disorder. American Journal of Psychiatry. 147(8), 1008-1013.

Piccinino, S. (1990). The nursing care challenge. Borderline patients. Journal of Psychosocial Nursing, 28(4), 2227.

Silk, K., Eisner, W., Allport, C., Demars, C., Miller, C., Justice, R., \& Lewis, M. (1992, May). Interrupted inpatient treatment of borderline personality disorder. $\mathrm{Pa}$ per presented at the 145th annual meeting of the American Psychiatric Association, Washington, DC.

Vaillant, G. (1992). The beginning of wisdom is never calling a patient a borderline; or, the clinical management of immature defenses in the treatment of individuals with personality disorders. Journal of Psvchotherapy Practice and Research, 1(2), 117-134.

Westen, D. (1991). Cognitive-behavioral interventions in the psychoanalytic psychotherapy of borderline personality disorder. Clinical Psychology Review. 1I, 211-230.

Whitfield, C. (1990). A Gift to Myself. Deerfield Beach, FL: Health Communications.

Woititz, J., \& Garner, A. (1990). Lifeskills for Adult Children. Deerfield Beach, FL: Health Communications. 